\title{
Knowledge of novel coronavirus disease (COVID-19) among dental surgeons of Nepal: a nationwide study
}

\author{
Mukesh Kumar Sah ${ }^{1 *}$ (D, Abanish Singh ${ }^{2}$ (D) and Raj Kumar Sangroula ${ }^{3}$ (D)
}

\begin{abstract}
Background: COVID-19 is an emerging respiratory disease caused by a novel coronavirus. There is not much evidence assessing the knowledge of dental surgeons regarding COVID-19. This study was conducted to assess the knowledge of COVID-19 among dental surgeons of Nepal.

Methods: A web-based cross-sectional study was conducted among registered dental surgeons of Nepal. Ethical approval was obtained. Consent was taken, and knowledge on COVID-19 was assessed via a pre-tested structured questionnaire using Google form. The form was emailed to the participants. Descriptive analysis was performed using frequency, percentage, median and inter-quartile range. Man-Whitney test and Kruskal-Wallis tests were carried out to see the difference in knowledge score. $P$-value $<0.05$ was considered statistically significant.
\end{abstract}

Results: Total 227 dental surgeons responded to the questionnaire (male: 46.4\%; female: 53.7\%). Almost twothird (65.2\%) of the respondents were B.D.S. (Bachelor of Dental Surgery) graduates. Only 29.1\% worked in the government hospitals. $17.6 \%$ were currently involved in COVID-19 management. Of the participants, $87.7 \%$ knew about the condition of the requirement of Personal Protective Equipment (PPE) but only 29.1\% could correctly answer the framed question for PPE. The median knowledge score calculated was 14.0 (8.0-18.0). The bivariate analysis showed a statistically significant difference in knowledge score among the age group $\geq 30$ years and $<30$ years $(p=0.013)$; M.D.S. (Master of Dental Surgery) graduate and B.D.S. graduate (0.041); dental surgeons of government healthcare facilities and other healthcare facilities ( $p<0.001$ ); dental surgeons of COVID-19 centers and non-COVID-19 centers (0.002).

Conclusion: The dental surgeons of Nepal have a good knowledge of COVID-19, and they can be utilized for assisting in the management of COVID-19 cases in Nepal.

Keywords: Case management, COVID-19, Dental surgeons, Knowledge

\section{Background}

Coronavirus disease (COVID-19) is an emerging respiratory disease caused by a novel coronavirus [1]. It was first reported to World Health Organization (WHO) country office in China from Wuhan city, China on 31 December 2019 [1]. The highly infectious disease has

\footnotetext{
*Correspondence: sahmukeshkumar88@gmail.com

'Department of Emergency Medicine and General Practice, Patan Academy of Health Sciences, Lalitpur, Bagmati Province, Nepal

Full list of author information is available at the end of the article
}

infected more than 6 million people with the reported deaths of more than 378,000 and spreading to 213 countries worldwide [2]. WHO declared this outbreak as a Public Health Emergency of International concern on 30 January 2020 [2].

COVID-19 is largely spread by human-to-human transmission through droplet infection with some cases of feco-oral and direct transmission [3]. The incubation period is 2-14 days [3]. The main clinical symptoms include fever, dry cough, fatigue, myalgia and dyspnea.

(c) The Author(s). 2020 Open Access This article is licensed under a Creative Commons Attribution 4.0 International License, which permits use, sharing, adaptation, distribution and reproduction in any medium or format, as long as you give appropriate credit to the original author(s) and the source, provide a link to the Creative Commons licence, and indicate if changes were made. The images or other third party material in this article are included in the article's Creative Commons licence, unless indicated otherwise in a credit line to the material. If material is not included in the article's Creative Commons licence and your intended use is not permitted by statutory regulation or exceeds the permitted use, you will need to obtain permission directly from the copyright holder. To view a copy of this licence, visit http://creativecommons.org/licenses/by/4.0/ The Creative Commons Public Domain Dedication waiver (http://creativecommons.org/publicdomain/zero/1.0/) applies to the data made available in this article, unless otherwise stated in a credit line to the data. 
There is no antiviral treatment or vaccine recommended for COVID-19. Hence, WHO, along with national and international health agencies, has highly recommended preventive strategies like frequent hand washing, social distancing, and lockdown. Despite such stringent global efforts, the numbers of cases are increasing day by day. This has led to increased load among medical doctors and nurses to combat this pandemic. Now, it is seen that the available health facilities and medical doctors are running short and dental doctors are being called upon to deal with the pandemic $[4,5]$.

The doctor-patient ratio of Nepal is 0.17 per 1000 population-substantially less than the WHO recommendation of 2.3 doctors per 1000 population [6].The number of COVID-19 cases are increasing in Nepal as well. As of August 20, 2020, the official data of Nepal shows 29,645 people infected with COVID-19 and 126 registered deaths due to COVID-19 [7]. Now, many health care workers are already infected with COVID-19 leading to a shortage of human resources to combat COVID-19 that has led for an emergency call for recruitment of health care professionals [8]. If the medical doctor runs short in Nepal to deal with COVID-19, then dental surgeons might be of significant support to deal with this pandemic. Dental surgeons are the most efficiently trained doctors regarding the medical diseases after medical doctors as they share a common curriculum of 3 years out of the 5.5 years. There are many online training manuals by WHO and different health agencies to prepare all health care professionals for COVID-19 [9].There are few evidences assessing the knowledge of dental surgeons regarding COVID-19 [10, 11]. Hence, this study was conducted to assess the knowledge of COVID-19 among dental surgeons of Nepal.

\section{Methods}

\section{Study design, study population and sample size}

A web-based quantitative descriptive cross-sectional study was carried out from 10 March to 25 March, 2020. This study considered $(95 \% \mathrm{CI})$ and $95 \%$ power to estimate the sample size. For this purpose, $65.7 \%$ (p) was considered from a study [12] conducted among health workers on knowledge and perception related to COVID 19, and the calculated sample size was 200. A structured questionnaire using Google forms was emailed to all the Nepal Medical Council registered dental surgeons. Emails were obtained from the Nepal Dental Association dentist directory. A total of 227 registered dentists filled the Google forms by May 25, 2020, which were analyzed.

\section{Data collection procedures and ethical approval}

A pre-tested structured questionnaire using Google form was emailed to collect data from registered dental surgeons of Nepal. Ethical approval was taken from the Ethical Review Board (ERB) of Nepal Health Research Council (Reg. no.: 2383). The Google forms emailed had informed consent form with details of the study. A reminder email was sent to all the previously emailed dental surgeons after a week of the first email. Confidentiality of the information was ensured by maintaining privacy.

\section{Study variables \\ Socio-demographic variables}

Age of the participants was categorized as less than 30 and more than or equal to 30 . The gender of the participants was categorized as male and female. The degree of the dental surgeons was categorized as Bachelor of Dental Surgery (B.D.S.) and Master of Dental Surgery (M.D.S.). The working province of the participants included all the seven provinces of Nepal in which Karnali and Sudurpaschim Province were merged for bivariate analysis. Type of hospital/ health center where the dental surgeons worked was categorized as Government, Private clinic, Private hospital, and semi-government. The level of hospital/health center was categorized as Primary, Secondary and Tertiary levels. Working hospitals of the dental surgeons was categorized into COVID-19 center and non-COVID-19 center. Involvement in COVID-19 management was categorized into "Yes" and "No". Received training on COVID-19 management was categorized into "Yes" and "No".

\section{Knowledge on COVID-19}

For assessment of knowledge on COVID-19 among dental surgeons of Nepal, a 14-items questionnaire tool was developed from the published literatures [10-12]. Face and content validation of tool was done by the researchers. Further, the tool was pre-tested among 25 dental surgeons to check for reliability. These 25 dental surgeons were not included in the main study. The tool included questions related to the origin of Coronavirus, case definition of COVID-19, contact and contact tracing, condition of requirement of PPE, principles of Rapid Diagnostic Test (RDT) and Reverse Transcription Polymerase Chain Reaction (RT-PCR) test, sample collection and transportation, preventive measures (quarantine and isolation), waste management, clinical features of COVID-19, roles and responsibility of different level of hospitals for COVID-19 management and public awareness for the prevention of COVID-19. The cumulative score of the knowledge related questions ranged from 0 to 18 (Table 1 ).

\section{Statistical analysis}

All the responses from Google forms were exported to Microsoft Excel 2016 and were exported to SPSS version 
Table 1 shows the score related to each component

\begin{tabular}{lc}
\hline Knowledge components & Knowledge score \\
\hline Case definition of COVID-19 & 3 \\
Definition of contact and contact tracing & 1 \\
Transmission of COVID-19 & 1 \\
Need and use of PPE & 1 \\
Test for COVID-19 & 1 \\
Sample collection and transportation & 1 \\
Preventive measures for COVID-19 & 1 \\
Waste management & 1 \\
Clinical features & 2 \\
Epidemiological patterns & 1 \\
Government assigned hospital levels in Nepal for management of COVID-19 & 1 \\
Public awareness for prevention of COVID-19 & 1 \\
Overall knowledge score on CovID-19 & 18
\end{tabular}

23 (SPSS, Inc., Chicago, IL, USA) software. Descriptive analysis was performed using frequency, percentage, median and inter-quartile range. After the normality test of the knowledge score, it was found that the overall knowledge score was non-normal (skewed). Man-Whitney test (for variables with two categories) and Kruskal-Wallis test (for variables with more than two categories) were carried out to see the difference in knowledge score between different socio-demographic variables. $P$-value < 0.05 was considered statistically significant.

\section{Results}

This was a web-based survey conducted to assess the knowledge of COVID-19 among dental surgeons of Nepal. Total 227 dental surgeons responded to the questionnaire (male: $46.4 \%$; female: $53.7 \%$ ). Almost two-third $(65.2 \%)$ of the respondents were B.D.S. graduates. More than $80 \%$ of the respondents were from three provinces (Province 1, Province 2, and Bagmati Province). It was seen that only $29.1 \%$ of the dental surgeons worked in government hospitals, and more than $50 \%$ of the dental surgeons worked in a tertiary level health care facility. More than one-third (35.7\%) of the dental surgeons are currently working in a health facility that is a COVID-19 center. It was seen that $17.6 \%$ of dental surgeons are currently involved in COVID-19 management. Only $28.2 \%$ of dental surgeons received COVID-19 management training, but the majority of them had received online training (71.8\%) (Table 2).

The knowledge of COVID-19 was assessed via a yesno' questionnaire followed by a conceptually framed question that checked the accurate knowledge responded to those 'yes-no' questionnaires. Almost all dental surgeons were aware of the origin of Coronavirus. $88.5 \%$ knew about the case definition of COVID-19, but
79.7\% could give the correct answer regarding the same. Of the participants, $87.7 \%$ of the dental surgeons knew about the condition of the requirement of Personal Protective Equipment (PPE), but only $29.1 \%$ could correctly answer the framed question for PPE. Similarly, 93.8\% knew about the preventive measures (quarantine and isolation), but only $59.5 \%$ could correctly answer the framed questionnaire (Table 3).

The knowledge score was also assigned for the correct answer to the questionnaires and the median knowledge score calculated was 14.0 (8.0-18.0).

The bivariate analysis showed that the knowledge score of dental surgeons of age group $\geq 30$ years had better knowledge compared to the age group $<30$ years, and the difference was statistically significant $(p=0.013)$. The knowledge score of male dental surgeons was more compared to female dental surgeons, but it was not statistically significant (0.063). M.D.S. trained dental surgeons had more knowledge of COVID-19 compared to B.D.S. trained dental surgeons, which was statistically significant $(0.041)$. The dental surgeons working in government healthcare facilities had better knowledge scores compared to other healthcare facilities, and it was statistically significant $(p<0.001)$. Similarly, the dental surgeons working in COVID-19 centers had higher knowledge compared to non-COVID-19 centers, and the difference was statistically significant (0.002). The dental surgeons involved in the management of COVID-19 patients had better knowledge scores than the ones not involved in COVID-19 management, and it was statistically significant $(0.004)$. But, there was no statistically significant difference between the knowledge score of dental surgeons who received training on COVID-19 and who did not $(p=0.853)$ (Table 4$)$. 
Table 2 Socio-demographic Characteristics

\begin{tabular}{|c|c|c|}
\hline Characteristics & Dental Surgeons $(n=227)$ & Percentage (\%) \\
\hline \multicolumn{3}{|l|}{ Age } \\
\hline$<30$ years & 128 & $56.4 \%$ \\
\hline$\geq 30$ years & 99 & $43.6 \%$ \\
\hline \multicolumn{3}{|l|}{ Gender } \\
\hline Male & 105 & $46.3 \%$ \\
\hline Female & 122 & $53.7 \%$ \\
\hline \multicolumn{3}{|l|}{ Education level } \\
\hline Bachelor level (B.D.S.) & 148 & $65.2 \%$ \\
\hline Masters level (M.D.S.) & 79 & $34.8 \%$ \\
\hline \multicolumn{3}{|l|}{ Province } \\
\hline Province 1 & 63 & $27.8 \%$ \\
\hline Province 2 & 26 & $11.5 \%$ \\
\hline Bagmati Province & 99 & $43.6 \%$ \\
\hline Gandaki Province & 16 & $7.0 \%$ \\
\hline Province 5 & 18 & $7.9 \%$ \\
\hline Karnali + Sudurpaschim Province & 5 & $2.2 \%$ \\
\hline \multicolumn{3}{|l|}{ Type of hospital/ health care center } \\
\hline Government & 66 & $29.1 \%$ \\
\hline Private Clinic & 58 & $25.6 \%$ \\
\hline Private Hospital & 80 & $35.2 \%$ \\
\hline Semi-Government (NGO, INGO, Public Private Partnership) & 23 & $10.1 \%$ \\
\hline \multicolumn{3}{|l|}{ Hospital level } \\
\hline Primary level & 50 & $22.0 \%$ \\
\hline Secondary level & 58 & $25.6 \%$ \\
\hline Tertiary level & 119 & $52.4 \%$ \\
\hline \multicolumn{3}{|l|}{ Working hospital/healthcare facility } \\
\hline COVID-19 Center & 81 & $35.7 \%$ \\
\hline Non-COVID1-19 Center & 146 & $64.3 \%$ \\
\hline \multicolumn{3}{|l|}{ Involvement in COVID-19 management } \\
\hline Yes & 40 & $17.6 \%$ \\
\hline No & 187 & $82.4 \%$ \\
\hline \multicolumn{3}{|l|}{ Ever received COVID-19 management training } \\
\hline Yes & 64 & $28.2 \%$ \\
\hline No & 163 & $71.8 \%$ \\
\hline \multicolumn{3}{|l|}{ If yes, the type of training received $(n=64)$} \\
\hline Web based training & 46 & $71.8 \%$ \\
\hline Workshop/Seminar & 18 & $28.2 \%$ \\
\hline
\end{tabular}

\section{Discussions}

COVID-19 has imposed a global impact affecting all the sectors and has created a chaotic situation at healthcare facilities. Despite putting a stringent effort by the government like lockdown and promoting preventive measures like frequent hand-washing, use of masks, and social distancing, the numbers of cases are increasing day by day. Globally, the healthcare facilities are running short of trained medical doctors as well. Now in many countries, dental surgeons are being called upon to assist in the management of COVID-19 cases. The preparedness of the healthcare personals to combat any pandemic has been assessed by evaluating the knowledge of the disease [13-15]. 
Table 3 Knowledge on COVID-19 $(n=227)$

\begin{tabular}{|c|c|c|}
\hline Knowledge questions with 'yes' and 'no' responses & $\begin{array}{l}\text { Dental Surgeons with "yes" } \\
\text { responses (\%) }\end{array}$ & $\begin{array}{l}\text { Dental Surgeons with correct } \\
\text { responses (\%) }\end{array}$ \\
\hline Origin of Coronavirus & $224(98.7 \%)$ & $224(98.7 \%)$ \\
\hline Case definition of COVID-19 & $201(88.5 \%)$ & $181(79.7 \%)$ \\
\hline Contact and contact tracing & $201(88.5 \%)$ & $215(94.7 \%)$ \\
\hline Condition of requirement of PPE & $199(87.7 \%)$ & $66(29.1 \%)$ \\
\hline Principles of RDT and RT-PCR test & $167(73.6 \%)$ & $178(78.4 \%)$ \\
\hline Sample collection and transportation & $161(70.9 \%)$ & $175(77.1 \%)$ \\
\hline Preventive measures (quarantine and isolation) & $213(93.8 \%)$ & $135(59.5 \%)$ \\
\hline Waste management & $109(48.0 \%)$ & $126(55.5 \%)$ \\
\hline Clinical features of COVID-19 & $224(98.7 \%)$ & $153(67.4 \%)$ \\
\hline $\begin{array}{l}\text { Roles and responsibility of different level of hospitals for COVID-19 } \\
\text { management }\end{array}$ & $130(57.3 \%)$ & $143(63.0 \%)$ \\
\hline Public awareness for prevention of COVID-19 & $214(94.3 \%)$ & $224(98.7 \%)$ \\
\hline Overall knowledge score on COVID-19 & $14.0(8.0-18.0)$ & \\
\hline
\end{tabular}

This study assessed the knowledge of COVID-19 among the Nepal Medical Council registered dental surgeons. The median knowledge score of 14.0 (8.0-18.0) indicates a good knowledge of COVID-19 among dental surgeons of Nepal which was similar to the study conducted by Kamte et al. [11] The majority of the dental surgeons who responded were B.D.S. graduates $(65.2 \%)$ and female dental surgeons $(53.7 \%)$. A similar finding was seen in the survey conducted among Jordanian dentist [16] but was different from the survey conducted among the north Italian dentist [17] where male dentist participated more. More than $80 \%$ of the dental surgeons were from province 1,2 , and Bagmati province. The findings were in accordance with the study by Shrestha et al. where it explains the distribution of dental surgeons throughout Nepal [18]. It was seen that $17.6 \%$ of dental surgeons were involved in the management of COVID-19 cases. There is no published evidence to explicitly look into the scope for utilization of dental surgeons for the management of COVID-19 patients, but there are pieces of literature that have looked into the knowledge of COVID-19 among dentist [10, 11, 16, 17].

This was a nation-wide study and it was promising to know that almost all the dentists were aware of the origin of COVID-19. The high infectivity of COVID-19 has alarmed to keep the healthcare personals safe. If not so, then the infected asymptomatic healthcare personals might be the carrier and be the medium of transmission. Hence, PPE has been recommended by WHO to be used compulsorily while dealing with suspected/diagnosed cases of COVID-19 [9]. Of the participants, $87.7 \%$ of the dental surgeons were aware of the condition of requirement of PPE but only $29.1 \%$ could answer the framed question regarding the same. Similarly, 93.8\% knew about the preventive measures (quarantine and isolation), but only 59.5\% could correctly answer the framed questionnaire. Similar results were demonstrated by Kamte et al. where only $43.7 \%$ were sensitized about the $\mathrm{WHO}$ guidelines for COVID-19 prevention [11].

In the medical field, an increase in age and experience improves the knowledge of the clinicians. The senior clinicians are mostly postgraduates. They have better knowledge about research, and their practices are mostly evidence-based $[19,20]$. It was seen that dental surgeons of age group $\geq 30$ years had better knowledge scores compared to the age group $<30$ years $(p=0.013)$. During the postgraduate training, the residents are trained about research and are updated with knowledge based on recent evidences. In contrast, very few institutions are seen to engage their undergraduates in such learning practices [21]. This might be the reason for M.D.S. graduate dental surgeons to have a statistically significant better knowledge score compared to B.D.S. graduates $(p=$ 0.041). These findings were similar to those of Kamte et al. [11] and Gupta et al. [22]. The dental surgeons (29.1\%) working in government healthcare facilities had a better knowledge score of COVID-19 compared to other healthcare facilities, and it was statistically significant $(p<0.001)$. It was a similar situation among Jordanian dentists where $22.8 \%$ were working in public service whereas it was only $6.82 \%$ of north Italian dentist associated with National health System [16, 17]. Similarly, the dental surgeons working in COVID-19 centers had higher knowledge compared to non-COVID-19 centers, and the difference was statistically significant $(0.002)$. This might be due to the reason that currently in Nepal, only government healthcare facilities are used to treat COVID-19 cases, and the healthcare personals are oriented and trained before the management of COVID-19 cases. 
Table 4 Comparison of knowledge score among different variables

\begin{tabular}{|c|c|c|}
\hline Characteristics & Median (Q1-Q3) & $P$-value \\
\hline \multicolumn{3}{|l|}{ Age in years } \\
\hline$<30$ & $14(12-15)$ & $0.013^{*}$ \\
\hline$\geq 30$ & $14(13-15)$ & \\
\hline \multicolumn{3}{|l|}{ Gender } \\
\hline Female & $13.5(12-15)$ & $0.063^{*}$ \\
\hline Male & $14(13-15)$ & \\
\hline \multicolumn{3}{|l|}{ Education level } \\
\hline BDS & $14(12-15)$ & $0.041^{*}$ \\
\hline MDS & $14(13-15)$ & \\
\hline \multicolumn{3}{|l|}{ Province } \\
\hline Province 1 & $14(13-15)$ & $0.010^{* *}$ \\
\hline Province 2 & $15(13-16)$ & \\
\hline Bagmati Province & $13(12-15)$ & \\
\hline Gandaki Province & $13.5(12-14.75)$ & \\
\hline Province 5 & $14(12.75-15)$ & \\
\hline Karnali+sudurpaschim Province & $15(14.5-16.5)$ & \\
\hline \multicolumn{3}{|l|}{ Type of Healthcare } \\
\hline Government & $15(14-16)$ & $<0.001^{* *}$ \\
\hline Private & $13(12-15)$ & \\
\hline Semi-government & $14(13-15)$ & \\
\hline \multicolumn{3}{|l|}{ Level of hospital/healthcare } \\
\hline Primary & $13.5(12-15)$ & $0.029^{* *}$ \\
\hline Secondary & $13(11-15)$ & \\
\hline Tertiary & $14(13-15)$ & \\
\hline \multicolumn{3}{|l|}{ Working Hospital } \\
\hline COVID-Center & $14(13-15.5)$ & $0.002^{*}$ \\
\hline Non-COVID Center & $13(12-15)$ & \\
\hline \multicolumn{3}{|c|}{ Involvement in COVID-19 management } \\
\hline Yes & $14.5(13-16)$ & $0.004^{*}$ \\
\hline No & $14(12-15)$ & \\
\hline \multicolumn{3}{|l|}{ Training on COVID-19 } \\
\hline Yes & $14(13-15)$ & $0.853^{*}$ \\
\hline No & $14(12-15)$ & \\
\hline
\end{tabular}

*Mann-Whitney test; **Kruskal-Wallis test; $p<0.05$ indicates statistically significant

Traditionally seminar, workshops, hands-on training with face to face interactive sessions was used for regular updates on recent evidence. The outbreak of COVID-19 has limited all the mass gathering and social events to decrease the transmission rates. The recent evidence suggests that online training can be of similar significance compared to on-site training, but further exploration is needed to establish it as fact [23, 24]. It was seen that $28.2 \%$ of the dental surgeons had received training COVID-19. But, there was no statistically significant difference between the knowledge score of dental surgeons who received training on COVID-19 and who did not $(p=0.853)$.

The strength of the study is that, it was a nation-wide study where the participating dental surgeons were from all the provinces. The calculated sample size was obtained, and the results can be generalized throughout Nepal. This study had some limitations, the web-based cross-sectional nature of the study design that is prone to selection bias and information bias on the respondent's side.

\section{Conclusion}

In conclusion, the dental surgeons of Nepal have a good knowledge of COVID-19. Based on the finding of this study, dental surgeons can be utilized for assisting in the management of COVID-19 cases when needed. But, they are to be oriented and trained before, about management protocols of COVID-19.

\section{Supplementary Information}

The online version contains supplementary material available at https://doi. org/10.1186/s12879-020-05620-4.

Additional file 1. Questionnaire.

\section{Abbreviations}

COVID-19: Coronavirus Disease - 19; B.D.S.: Bachelor of Dental Surgery; M.D.S.: Master of Dental Surgery; PPE: Personal Protective Equipment; Cl: Confidence Interval; ERB: Ethical Review Board; RDT: Rapid Diagnostic Test; RT-PCR: Reverse Transcription - Polymeric Chain Reactions

Acknowledgements

We acknowledge Mr. Raj Kumar Subedi from Bhaskar-Tehshree Memorial Foundation, Nepal for his contribution in formatting and editing the manuscript and Dr. Annu Kumari Sah, a private practitioner for her help in online data collection.

Authors' contributions

MKS, AS, and RKS conceived, conceptualized and designed the study. AS and MKS collected the data. RKS analyzed the data. All authors drafted the manuscript, critically read the manuscript, and agreed to its submission and publication. The author(s) read and approved the final manuscript.

Funding

None.

Availability of data and materials

The data supporting the findings of this article are available from the corresponding author.

Ethics approval and consent to participate

Ethical approval was obtained from Ethical Review Committee of Nepal Health Research Council, Kathmandu, Nepal (Committee's Ref. No: 2383) and informed consent were taken from the participants.

\section{Consent for publication}

Data collection was anonymous. No images or other personal details of participants are presented here. The participants were informed about the details collected via Google form and consent was taken for the use of their details in a scientific publication. 


\section{Competing interests}

The authors declare that they have no competing interests.

\section{Author details}

'Department of Emergency Medicine and General Practice, Patan Academy of Health Sciences, Lalitpur, Bagmati Province, Nepal. ${ }^{2}$ Narayani Hospital, Birgunj, Province 2, Nepal. ${ }^{3} \mathrm{Nepal}$ Public Health Research and Development Center, Shankhamul, New Baneshor, Kathmandu, Bagmati Province, Nepal.

Received: 2 July 2020 Accepted: 15 November 2020

Published online: 23 November 2020

\section{References}

1. Rolling updates on coronavirus disease (COVID-19): Summary. Available online: https://www.who.int/emergencies/diseases/novel-coronavirus-2019/ events-as-they-happen (Assessed on 2 June 2020).

2. Rolling updates on coronavirus disease (COVID-19). Available online: https:// www.who.int/emergencies/diseases/novel-coronavirus-2019 (Assessed on 2 June 2020).

3. World Health Organization. Novel coronavirus (COVID-19) situation. Available online: https:// https://experience.arcgis.com/experience/685 d0ace521648f8a5beeeee1b9125cd (Assessed on 2 June 2020).

4. Dentist can register to help with the state's COVID-19 pandemic response. Available online: https://www.cda.org/Home/News-and-Events/Newsroom/ Article-Details/dentists-can-register-to-help-with-states-covid-19-pandemicresponse (Assessed on 2 June 2020).

5. Coronavirus: Dentists to help state new staff hospitals. Available online: https://www.bbc.com/news/education-52050506 (Assessed on 2 June 2020).

6. Adhikari B, Mishra SR. Urgent need for reform in Nepal's medical education. Lancet. 2016;388(10061):2739-40.

7. Ministry of Health and population, Nepal. Latest updates on COVID-19. Available online: https://covid19.mohp.gov.np/\#/ (Assessed on 20 Aug 2020).

8. COVID-19 Health Emergency Situation application call. Available online: https://mohp.gov.np/en/news/632-2020-08-19-05-59-23 (Assessed on 20 Aug 2020).

9. Country and Technical Guidance- Coronavirus disease (COVID-19) Available online: https://www.who.int/emergencies/diseases/novel-coronavirus-2019/ technical-guidance (Assessed on 2 June 2020).

10. Mir F.A. Quadri, Mohammed A. Jafer, Ahmed Shaher Alqahtani, Somayah A. B. Al mutahar, Nouf I. Odabi, Amal A. Daghriri, Santosh K. Tadakamadla, Novel corona virus disease (COVID-19) awareness among the dental interns, dental auxiliaries and dental specialists in Saudi Arabia: A nationwide study. J Infec Publ Health. 2020;13(6):856-64.

11. Kamate SK, Sharma S, Thakar S, Srivastava D, Sengupta K, Hadi AJ, Chaudhary A, Joshi R, Dhanker K. Assessing knowledge, attitudes and practices of dental practitioners regarding the COVID-19 pandemic: a multinational study. Dental Med Problems. 2020:57(1):11-7.

12. Bhagavathula AS, Aldhaleei WA, Rahmani J, Mahabadi MA, Bandari DK. Novel Coronavirus (COVID-19) Knowledge and Perceptions: A Survey on Healthcare workers. medRxiv. 2020.

13. Olowookere SA, Abioye-Kuteyi EA, Adepoju OK, Esan OT, Adeolu TM, Adeoye TK, Adepoju AA, Aderogba AT. Knowledge, attitude, and practice of health workers in a tertiary hospital in Ile-Ife, Nigeria, towards Ebola viral disease. J Trop Med. 2015;2015:431317.

14. Shi Y, Wang J, Yang Y, Wang Z, Wang G, Hashimoto K, Zhang K, Liu H. Knowledge and attitudes of medical staff in Chinese psychiatric hospitals regarding COVID-19. Brain, Behav Immun Health. 2020;4:100064.

15. Alsahafi AJ, Cheng AC. Knowledge, attitudes and behaviours of healthcare workers in the Kingdom of Saudi Arabia to MERS coronavirus and other emerging infectious diseases. Int J Environ Res Public Health. 2016;13(12): 1214.

16. Khader $Y$, Al Nsour M, Al-Batayneh OB, Saadeh R, Bashier H, Alfaqih M, Al-Azzam S. Dentists' awareness, perception, and attitude regarding COVID19 and infection control: cross-sectional study among Jordanian dentists. JMIR Public Health Surveill. 2020;6(2):e18798.

17. Cagetti MG, Cairoli JL, Senna A, Campus G. COVID-19 Outbreak in North Italy: An Overview on Dentistry. A Questionnaire Survey. Int J Environ Res Public Health. 2020;17(11):3835.

18. Shrestha RM, Shrestha S, Kunwar N. Dentists in Nepal: a situation analysis. J Nepal Health Res Counc. 2017;15(2):187-92.
19. Masic I, Miokovic M, Muhamedagic B. Evidence based medicine-new approaches and challenges. Acta Inform Med. 2008;16(4):219.

20. Memarpour M, Fard AP, Ghasemi R. Evaluation of attitude to, knowledge of and barriers toward research among medical science students. Asia Pac Fam Med. 2015;14(1):1.

21. Singh A, Subedi K, Shrestha A, Bhagat T, Pyakurel P, Agrawal SK. Impact of community diagnosis Programme (CDP) on undergraduate students at BPKoirala Institute of Health Sciences. Kathmandu Univ Med J. 2019;66(2): 82-7.

22. Gupta N, Randhawa RK, Thakar S, Bansal M, Gupta P, Arora V. Knowledge regarding Zika virus infection among dental practitioners of tricity area (Chandigarh, Panchkula and Mohali), India. Nigerian Postgraduate Med J. 2016;23(1):33.

23. Aggarwal R, Gupte N, Kass N, Taylor H, Ali J, Bhan A, Aggarwal A, Sisson SD, Kanchanaraksa S, McKenzie-White J, McGready J. A comparison of online versus on-site training in health research methodology: a randomized study. BMC Med Educ. 2011;11(1):37.

24. Richmond H, Copsey B, Hall AM, Davies D, Lamb SE. A systematic review and meta-analysis of online versus alternative methods for training licensed health care professionals to deliver clinical interventions. BMC Med Educ. 2017;17(1):227.

\section{Publisher's Note}

Springer Nature remains neutral with regard to jurisdictional claims in published maps and institutional affiliations.
Ready to submit your research? Choose BMC and benefit from:

- fast, convenient online submission

- thorough peer review by experienced researchers in your field

- rapid publication on acceptance

- support for research data, including large and complex data types

- gold Open Access which fosters wider collaboration and increased citations

- maximum visibility for your research: over $100 \mathrm{M}$ website views per year

At BMC, research is always in progress.

Learn more biomedcentral.com/submissions 